\title{
Overview of NASA's Thermal Control System Development for Exploration Project
}

\author{
Ryan A. Stephan \\ NASA Johnson Space Center
}

\begin{abstract}
NASA's Constellation Program includes the Orion, Altair, and Lunar Surface Systems project offices. The first two elements, Orion and Altair, are manned space vehicles while the third element is broader and includes several subelements including Rovers and a Lunar Habitat. The upcoming planned missions involving these systems and vehicles include several risks and design challenges.

Due to the unique thermal environment, many of these risks and challenges are associated with the vehicles' thermal control system. NASA's Exploration Systems Mission Directorate (ESMD) includes the Exploration Technology Development Program (ETDP). ETDP consists of several technology development projects. The project chartered with mitigating the aforementioned risks and design challenges is the Thermal Control System Development for Exploration Project. The risks and design challenges are addressed through a rigorous technology development process that culminates with an integrated thermal control system test. The resulting hardware typically has a Technology Readiness Level (TRL) of six. This paper summarizes the development efforts being performed by the technology development project. The development efforts involve heat acquisition and heat rejection hardware including radiators, heat exchangers, and evaporators. The project has also been developing advanced phase change material heat sinks and performing assessments for thermal control system fluids.
\end{abstract}

\section{INTRODUCTION}

In early 2004, President Bush announced a bold vision for space exploration. One of the goals included in this vision is a human return to the moon by 2020 . In response to this vision, NASA established the Constellation Program, which includes several project offices. NASA has also established a separate program office whose charter is to advance technologies to a Technology Readiness Level (TRL) of six to support future exploration missions. This technology development program is referred to as the Exploration Technology Development Program (ETDP). The aforementioned Constellation Program serves as the primary customer for ETDP.
ETDP currently consists of 24 separate projects ranging from software development to entry descent and landing. Also included in this program portfolio is the Thermal Control System Development for Exploration project. This project, herein referred to as the Advanced Thermal project, is chartered with mitigating thermal risks and design challenges for various elements within the Constellation program.

The Advanced Thermal project is currently developing technologies for three difference Constellation elements. These elements include Orion, Altair, and Lunar Surface Systems (LSS). Orion is the manned capsule that will be used to transport crew to the International Space Station (ISS) and Lunar orbit. The second Advanced Thermal project customer is Altair. Altair is the Lunar lander element that will be used to transport crewmembers to and support them while living on the Lunar surface for short mission durations. The third, and final, customer is the Lunar Surface Systems project. The Advanced Thermal project is developing technologies for two elements within the LSS project. The first element is the Lunar Habitat which serves as the long-term habitat for astronauts while located on the Lunar surface. The second element is the Lunar Electric Rover (LER), which is a pressurized rover that will be used to house and transport crewmembers.

The current paper will describe the process for generating the Advanced Thermal project's technical content and the technology development process used to advance the technology readiness level to six. The current document will also briefly introduce the various technology developments currently underway. The majority of these efforts are also described in other papers $x, x, x, x, x$ at the current conference. These papers should be referenced for a more exhaustive description of a particular development task.

\section{PROJECT CONTENT GENERATION}

In addition to mitigating key Constellation Program Office (CxPO) thermal risks, the Advanced Thermal project also performs technology development based on discussions with members of the space thermal community. These development opportunities focus on further investigating novel concepts such as Sublimator 
Driven Coldplate ${ }^{1}$ that result from literature surveys and conversations amongst project members and the NASA community. The technology development project also seeks to identify unique applications using traditional hardware (i.e. transient sublimator) within the CxPO projects. The final source for project content is the identification of performance improvement opportunities (i.e. advanced phase change material heat sinks, variable heat rejection radiators, etc...). These performance advancements typically involve reducing hardware mass, but also include improvements in hardware maturity, reliability, and thermal performance.

To ensure that the technology development program is meeting the customer's technology needs, CxPO has established a Technology Prioritization Process (TPP). This "thermal discipline specific" part of this process is depicted graphically in Figure 1.

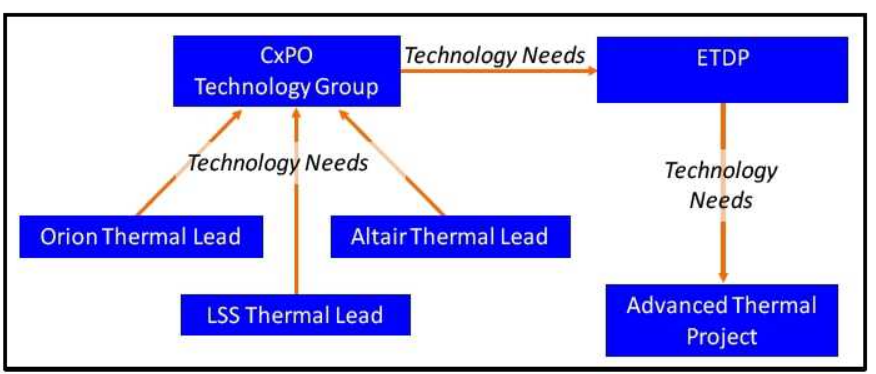

Figure 1. The Constellation Program's Technology Prioritization Process used to deliver technology development needs to the technology development project.

In the TPP, the Constellation thermal discipline leads for each of the three projects (Orion, LSS, and Altair) submit their technology development needs to a CxPO group that is responsible for prioritizing these needs. Once the list of technologies is prioritized amongst all of the vehicle disciplines, it is submitted to the technology development program, ETDP. ETDP then provides that list of needs to the relevant projects (i.e. thermal needs are submitted to the thermal project). The Advanced Thermal project is currently addressing a total of eleven technology needs. Of these needs, nine were classified as having a ranking of "critical", which is the highest classification. Another important step to ensuring that the CXPO technology needs are being satisfied is continual communication between the various CxPO thermal leads and the Advanced Thermal project manager. This communication path allows the technology development project to be flexible in meeting the customer's needs. It also helps to avoid any confusion or loss of information that could occur with the aforementioned technology prioritization process.

\section{TECHNOLOGY DEVELOPMENT PROCESS}

The project's technology development process typically begins with the hardware component possessing a technology readiness level of two or three. The first step in the process is the completion of coupon-level bench top tests. The objective of these tests is to better understand the basic physics and the critical development challenges associated with the technology. This phase is often followed by a design and analysis cycle focusing on addressing the previously defined development challenges. The design and analysis cycle culminates in detailed drawings for an Engineering Development Unit (EDU), which is a scaled-down model addressing the key technology issues. The EDU goes through a rigorous test program and new, correlated, thermal models are developed based on the previous test results. After completing the initial EDU tests and the subsequent thermal models, another design and analysis cycle is performed. During this second design and analysis cycle, the EDU performance data is assessed, performance improvements are recommended, and detailed requirements are defined. The result of the second design and analysis cycle is the generation of drawings and the fabrication of prototype hardware. The prototype hardware is then tested as a stand-alone entity to verify its performance.

The technology development process finally culminates with an integrated thermal test. The integrated test is performed in an environment relevant to the supporting vehicle (i.e. Altair) and simultaneously includes all of the previously developed hardware prototypes. The primary difference between the integrated test and the previous prototype tests is that the integrated test involves all of the developed hardware as an integrated thermal control system. At the conclusion of the integrated test, the developed technologies possess a TRL six which is defined as system/subsystem model or prototype demonstration in a relevant environment (ground or space).

The project is required to complete the integrated test in advance of the customer's Preliminary Design Review (PDR). Generally, the Advanced Thermal project strives to complete the integrated test approximately one year prior to the customer's PDR. After completing this test, the prototype hardware and the associated data package are delivered to the customer. The Advanced thermal project currently has four CxPO customers as shown in Table 1. This table also includes the planned dates for the customer's PDR.

Table 1. Advanced Thermal Project's Customers and the Corresponding PDR Dates.

\begin{tabular}{|c|c|}
\hline CxPO Customer & Planned PDR Date \\
\hline \hline Altair & July 2013 \\
\hline $\begin{array}{c}\text { Orion Lunar } \\
\text { Block Upgrade }\end{array}$ & July 2013 \\
\hline Lunar Electric Rover & April 2015 \\
\hline Lunar Habitat & November 2014 \\
\hline
\end{tabular}

PROJECT CONTENT AND TECHNOLOGY DEVELOPMENT TASKS 
The project includes several technical tasks spanning the three functions of an effective thermal control system. The three critical functions are heat acquisition, heat transport, and heat rejection. The following section will be divided into five subelements in accordance with the project's Work Breakdown Structure (WBS) as shown in Figure 2.

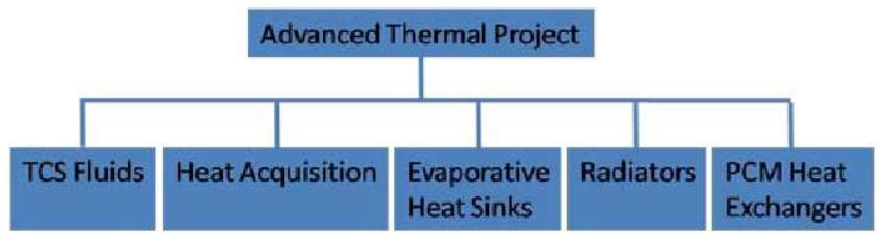

Figure 2. Partial Work Breakdown Structure (WBS) for Advanced Thermal Project.

\section{THERMAL CONTROL SYSTEM FLUIDS}

The overwhelming majority of United States' manned space vehicles have used a pumped fluid loop as the primary means of thermal control during the mission. These fluids have ranged from an ethylene glycol/water mixture on Apollo to the Orbiter with water (internal loop) and Freon $® 21$ (external loop). The current baseline thermal control system design for Orion, Altair, and the Lunar Habitat also depend on a mechanically pumped fluid loop. Currently, a mixture of propylene glycol and water is the baseline internal working fluid for the aforementioned CxPO projects. This fluid formulation has never been used for a manned vehicle so there is little long duration data for this fluid in a flight-like thermal control system.

As discussed in last year's overview paper $^{2}$, the Advanced Thermal project planned and executed a successful fluids life test. This test was originally planned to demonstrate fluid compatibility over a period of ten years. Resultantly, the test was designed to run continuously for the ten year demonstration. The working fluid for this test was a 50/50 (by mass) mixture of DowFrost ${ }^{\mathrm{TM}} \mathrm{HD}$ and water. The fluid loop was designed to include all of the materials inherent in Orion's thermal control system design. In order to save mass, Orion had baselined the use of aluminum tubing, aluminum heat exchangers, and aluminum coldplates. Therefore, the fluids life test stakeholders were especially interested in replicating the expected ratio of wetted aluminum surface area to fluid volume. The life test design included two Surface Area Modules (SAMs). The SAMs were fabricated using a four inch square stainless steel housing and included several layers of stacked aluminum fin stock. The stainless steel housing was isolated from the aluminum fin stock by Teflon sheets in order to eliminate any potential for galvanic coupling. As reported last year, the life test was terminated after only two months because the system filters became clogged and rendered the system inoperable. Furthermore, the coolant $\mathrm{pH}$ increased from 10.1 at the beginning of the test to 12.2 at the test termination. Subsequent analyses have shown that the selected coolant was not compatible with the large ratio of wetted aluminum surface area to fluid volume.

Based on the results of this test, DowFrost ${ }^{T M} \mathrm{HD}$ was removed as the working fluid for the Orion thermal control system design. Orion personnel are currently in the process of evaluating alternative formulations of propylene glycol and water for use as the coolant for the internal pumped fluid loop. In parallel with the updated fluid evaluation, the Advanced Thermal project has designed and started fabrication of an updated fluids life test stand.

The updated test stand design leverages the previous life test cart, but includes several improvements based on lessons-learned. The updated test stand design incorporating several improvements is shown in Figure 3.

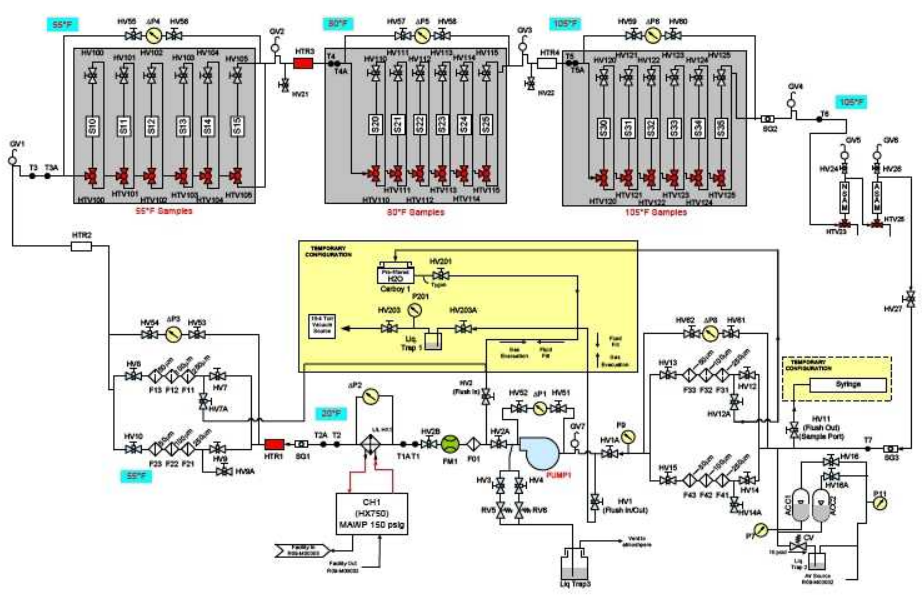

Figure 3. Updated fluid schematic for the thermal control system fluid life test.

There were four major design updates incorporated into the new test stand design. The first update involved redesigning the aluminum surface area modules to accurately represent the current Orion wetted surface area to fluid volume ratio. An additional surface area module was also designed. The second surface area module included nickel rather than aluminum. The second design modification incorporated gas vents at various locations around the test loop. These vents will be used to sample any gas that forms within the loop. The final design improvement is the inclusion of sight glasses to aid in the detection of gas or precipitate generation ${ }^{3}$.

\section{HEAT ACQUISITION}

An effective thermal control system must accomplish three basic functions (heat acquisition, heat transport, and heat rejection). One of these functions is the acquisition of excess thermal energy from the cabin air and other heat-generating devices. There are three subelements within this WBS element and each of them seeks to advance the state of the art by reducing hardware mass and volume.

SUBLIMATOR DRIVEN COLDPLATE - As reported last year $^{1}$, project personnel have invented and fabricated an 
advanced technology concept that combines all three thermal control system functions into a single piece of hardware. This novel hardware component is called the Sublimator Driven Coldplate (SDC) and has the potential of replacing the entire thermal control system with one hardware component. Another unique feature of this concept is that it does not use any power and includes no moving parts. The target application for the SDC is the Altair Ascent Module due to the low heat load, short transport distance, and short mission duration requirements for this vehicle. This technology would eliminate the need for a pumped fluid loop as all of the heat loads would be conductively coupled to a sublimator.

The first generation Engineering Development Unit (EDU) is shown in Figure 4.

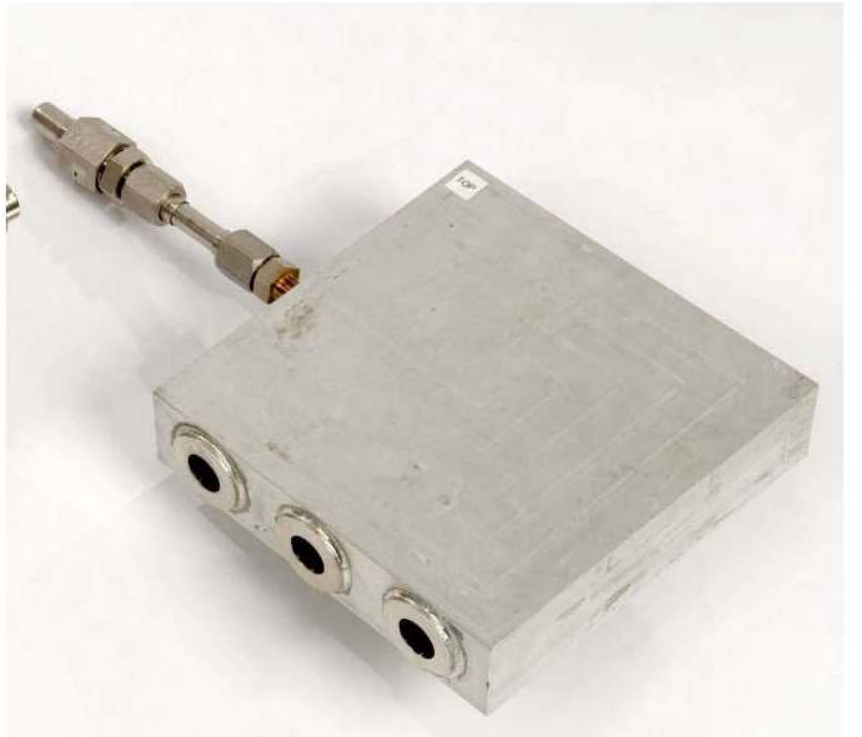

Figure 4. Sublimator driven coldplate engineering development unit.

The EDU that was delivered to JSC was approximately $6 " \times 6 " \times 2$ ". In the preceding photograph, the SDC was designed so that the heat-generating components would be directly mounted to the two $6 " \times 6$ " surfaces. For the purposes of the vacuum test program, a simple resistance heater was used to simulate the avionics heat load. The port extending to the top left of the photograph is the feedwater inlet tube and the SDC incorporates three $1 / 2$ " diameter stainless steel porous cylindrical tubes that serve as the sublimation plates.

The SDC design requirement was to maintain a surface temperature of less than $40^{\circ} \mathrm{C}$ with an evenly applied surface flux of $2 \mathrm{~W} / \mathrm{in}^{2}$. The SDC was exposed to a rigorous test program designed to verify that the unit met the design requirements and to understand its operation outside of the design envelope. The maximum recorded surface temperature when the SDC was subjected to a uniform heat flux of $2 \mathrm{~W} / \mathrm{in}^{2}$ was only $9^{\circ} \mathrm{C}$ far exceeding the design requirements. The steady state feedwater utilization was near unity for the duration of the test points.
COMPOSITE HEAT EXCHANGERS - Heat exchangers are traditionally used to transfer energy from one fluid loop to a second fluid loop. The use of composites for these types of hardware is an attractive alternative to traditional metallic heat exchangers. Carbon based composites have very high thermal conductivities making them more effective heat transfer devices. In addition, composites also have a high strength to mass ratio, which has the potential of reducing the hardware mass. The project has previously explored the benefit of using these advanced materials to fabricate radiators. However, heat exchanger construction is significantly different and requires a more detailed investigation.

Project personnel have successfully completed the design and fabrication of a composite air/liquid heat exchanger ${ }^{4}$. The performance requirements for this heat exchanger were based on the performance of an existing, mass-optimized, metallic air/liquid heat exchanger. The metallic heat exchanger was designed to transfer approximately $3.4 \mathrm{~kW}$ for a prescribed set of inlet conditions (inlet temperature and fluid flowrates). The composite air/liquid heat exchanger EDU is shown in Figure 5.

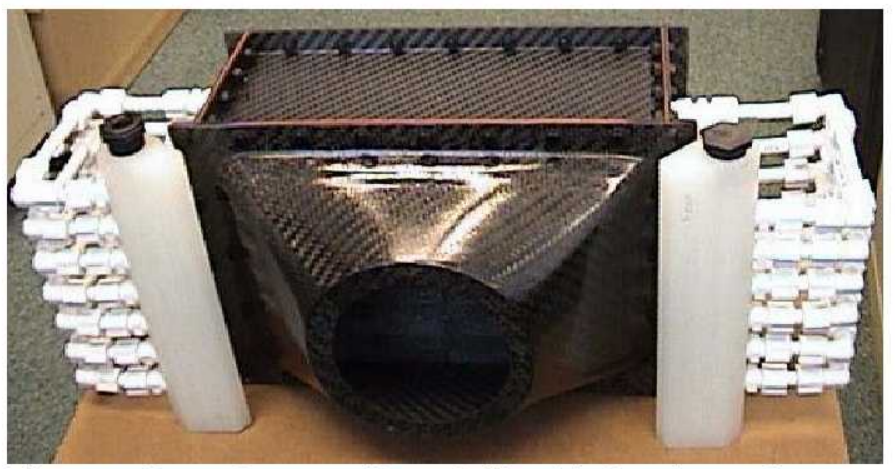

Figure 5. Composite air/liquid heat exchanger engineering development unit.

Note in the preceding photograph that the liquid inlet/exit manifolds are not representative of flight hardware. Rather these were intended to be functional in nature because the project does not envision the development of these to be overly challenging. The composite heat exchanger was $37 \%$ lighter than the metallic baseline. Unfortunately, the thermal performance of the composite heat exchanger was $13 \%$ less than the metallic baseline. To achieve a more representative comparison between the two heat exchangers, a "specific heat transfer" was quantified by simply dividing the heat transfer rate by the heat exchanger mass. The metallic heat exchanger had a specific heat transfer of $89 \mathrm{~W} / \mathrm{kg}$ while the composite heat exchanger's specific heat transfer was $121 \mathrm{~W} / \mathrm{kg}$ further providing evidence that this is a promising technology development pursuit.

The Advanced Thermal project is currently in the process of developing a prototype composite heat exchanger designed to meet the original heat exchanger requirements. The prototype heat exchanger design will 
be improved based on lessons-learned from the previous development effort. The next generation heat exchanger design is also focused on improving the design to allow for simpler heat exchanger fabrication.

MICROCHANNEL HEAT EXCHANGER - The technology development project has continued a previously started collaboration with Pacific Northwest National Laboratories (PNNL) to develop microchannel liquid/liquid heat exchangers.

The first step in the assessment of this technology was to establish a baseline for future comparison. To that end, a test cart was designed and used to assess the performance of a mass-optimized flight heat exchanger design for use on NASA's Crew Return Vehicle (X-38). This heat exchanger was designed to transfer energy from a warm de-ionized water loop to a cooler loop containing a mixture of ethylene glycol and water. The $2.7 \mathrm{~kg}$ heat exchanger was designed to transfer approximately $3.1 \mathrm{~kW}$ between the two loops. The X-38 heat exchanger performance specifications were supplied to PNNL as the requirements for a microchannel heat exchanger. PNNL designed, fabricated, and delivered a microchannel heat exchanger intended to meet those same performance specifications. Both the microchannel and baseline heat exchangers are shown in Figure 6.

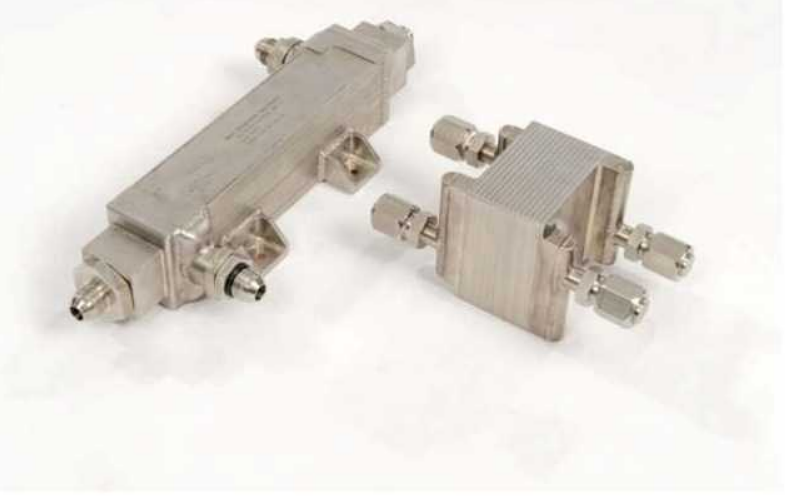

Figure 6. Baseline X-38 liquid/liquid heat exchanger (left) and PNNL's microchannel heat exchanger (right).

It is apparent from Figure 6 that the microchannel heat exchanger is significantly smaller than the baseline unit. In fact, the core volume of the microchannel heat exchanger is only $303 \mathrm{~cm}^{3}$ versus $793 \mathrm{~cm}^{3}$ for the X-38 baseline. In addition, the mass savings associated with this unit is approximately $0.65 \mathrm{~kg}$ or $24 \%^{5}$.

The microchannel heat exchanger test data has been shared with PNNL. The project was especially concerned about PNNL's failure to meet the pressure drop requirements on the cold loop. To that end, PNNL has used the test data to develop correlated heat exchanger models. These models were then used to conceptually design a next generation microchannel heat exchanger. The conceptual design shows improved mass and volume as compared to the first generation microchannel heat exchanger. This improvement was achieved while sacrificing the thermal performance of the unit. This sacrifice was acceptable because the first unit exceeded the thermal performance specifications. The mass and core volume for the conceptual design is 1.2 $\mathrm{kg}$ and $188 \mathrm{~cm}^{3}$, respectively.

The project is in the process of running a life test for the microchannel heat exchanger. This test is scheduled to run the baseline test point continuously for at least six months. The ensuing life test will provide insight into the performance of a microchannel heat exchanger over a long period of time similar to that expected for future spacecraft thermal control systems. The project is concerned that the microchannel heat exchanger may be susceptible to performance degradation due to the extremely small flow passages.

\section{HEAT REJECTION}

The third and final, critical function for an effective thermal control system is heat rejection. As the name implies, heat rejection is the process of rejecting the vehicle's waste heat to the local environment. This function is typically accomplished using radiators, but evaporators or Phase Change Material heat sinks can also be used to reject energy.

TRANSIENT SUBLIMATOR - The Lunar orbital environment presents very unique challenges for the thermal control system. Figure 7 shows the spatial variation of the Lunar surface temperature.
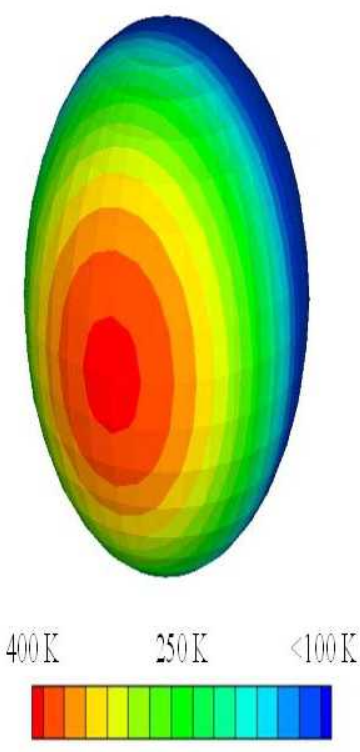

Figure 7. Spatial distribution of the Lunar surface temperature.

The hottest portion of the Lunar surface corresponds to the point directly aligned with the sun (subsolar point). In the preceding figure, the maximum surface temperature is approximately 400 Kelvin while the minimum temperature is less than 100 Kelvin on the dark side. 
The extreme surface variation results in a large swing in radiator sink temperatures while the vehicle is operating in Low Lunar Orbit (LLO). The large sink temperature variations are problematic because it is impractical (sometimes even impossible) to use a radiator as the sole means of heat rejection during LLO if the vehicle's radiators have a large IR incident load from the Lunar surface. The sink temperature corresponding to the location immediately above the subsolar point exceeds the setpoint temperature of the thermal control system. As a result, the vehicle's thermal control system must use a Supplemental Heat Rejection Device (SHReD) while the vehicle is in LLO. Figure 8 shows an example of the variability of a vehicle's heat rejection capability using only radiators for a beta angle of zero degrees and an orbital altitude of $100 \mathrm{~km}$. For Altair, these orbital parameters result in the worst case hot LLO environment.

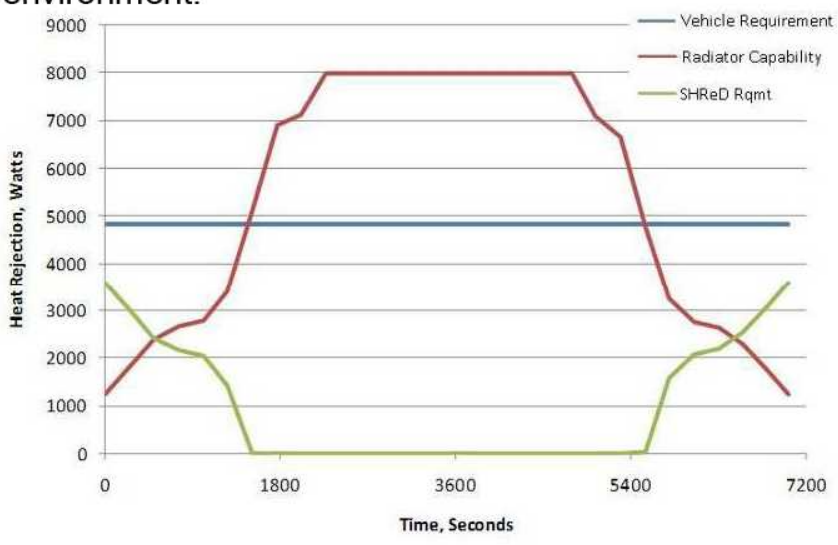

Figure 8. Vehicle heat rejection requirement (blue), radiator capability (red), and supplemental heat rejection requirement (green) as a function of mission time in Low Lunar Orbit.

The blue curve in Figure 6 represents the heat rejection requirement for the thermal control system. In this example, the vehicle heat rejection requirement is constant throughout the orbit. The red curve represents the vehicle radiator capability assuming a constant average radiator temperature where the radiator capability is defined as:

$\mathrm{Q}=\varepsilon \sigma \mathrm{A}\left(\mathrm{T}_{\mathrm{R}}^{4}-\mathrm{T}_{z}^{4}\right)$

Equation 1 throughout the orbit due to the changing Lunar surface temperature. In addition, the incident solar load will also vary throughout the orbit. The combination of these effects leads to a wide sink temperature variation in LLO. As depicted in Equation 1, the heat rejection capability of the proposed Altair radiator will vary as the sink temperature changes.

The thermal control system must be capable of rejecting the full vehicle heat load (approximately $4.8 \mathrm{~kW}$ in this example) throughout the entire orbit. Therefore, the supplemental heat rejection device must dissipate the difference between the heat rejection requirement and the radiator capability, which is shown by the green curve in Figure 8.

The selection of the proper SHReD depends on the duration of the LLO mission phase. For short mission durations, an evaporative heat sink would be used as the supplemental heat rejection device. A phase change material heat exchanger would likely be selected for longer mission durations. The baseline Altair thermal control system requires a sublimator for both Lunar ascent and descent. In addition, the same sublimator has been chosen as the SHReD during LLO. The thermal engineers designing the Orion thermal control system also identified a Low Earth Orbit (LEO) application for using a sublimator as a SHReD.

A spacecraft's thermal control system has never been designed to use a sublimator in this cyclical fashion. The technology development project completed a trade study and uncovered two potential problems with using a sublimator as a supplemental heat rejection device. Current sublimators have a minimum heat load requirement which would result in a poor orbit-averaged feedwater efficiency (or utilization). In addition, there is concern that the hardware may burst during periods when the sink temperature is relatively cold and the heat load on the sublimator is quite low or possibly nonexistent.

Where:

$$
\begin{aligned}
& Q=\text { Radiator heat rejection (Watts) } \\
& \varepsilon=\text { Infrared emissivity (Dimensionless) } \\
& \sigma=\text { Stefan-Boltzmann constant }\left(\mathrm{W} / \mathrm{m}^{2}-\mathrm{K}^{4}\right) \\
& \mathrm{A}=\text { Radiator surface area }\left(\mathrm{m}^{2}\right) \\
& \mathrm{T}_{\mathrm{R}}=\text { Average radiator temperature (Kelvin) } \\
& T_{\infty}=\text { Radiator sink temperature (Kelvin) }
\end{aligned}
$$

This figure clearly shows that the radiator capability varies throughout the Lunar orbit. This variability can be explained by studying Figure 7 . It is apparent that the IR backload incident upon the vehicle will change 
Throughout the previous year, the technology development project has executed a plan to mitigate the risk associated with rupturing the hardware while quantifying the expected Orbital Average Feedwater Utilization (OAFU). A sublimator coupon was fabricated and several operational modes were executed to quantify OAFU while assessing the hardware's susceptibility to rupturing during periods of low (or no) heat loads caused by ice expansion. The sublimator coupon is shown in Figure 9.

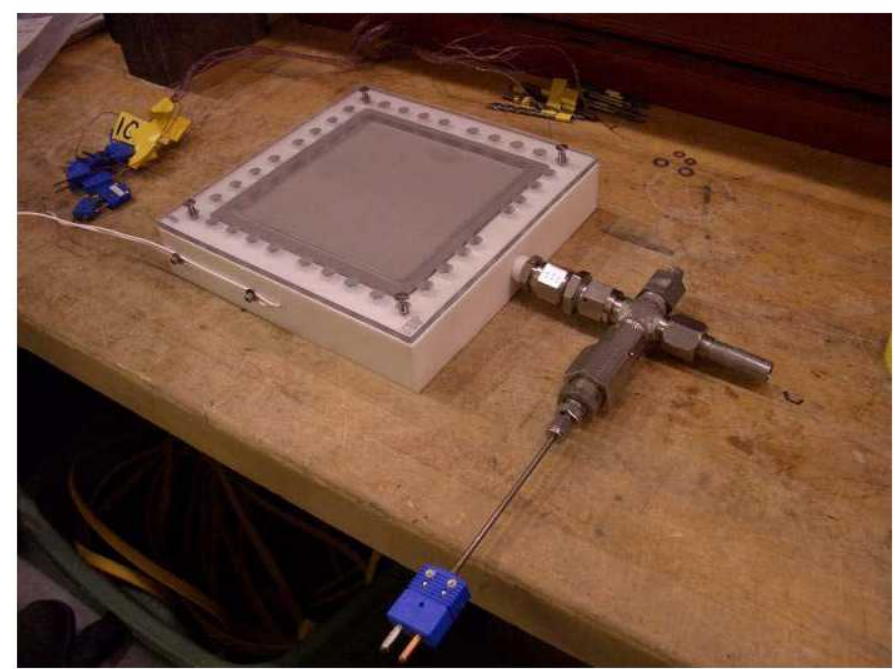

Figure 9. Photograph of the transient sublimator coupon used during the GFY 2009 test program.

The test program was run over a period of several weeks and resulted in several useful data points. The subsequent data analysis appeared to show a trend between feedwater valve timing and OAFU. For a given simulated orbit, OAFU appeared to be higher when the feedwater was stopped prior to the end of the heat load as compared to operational scenarios where the feedwater supply valve was left open for the entire twohour orbit period ${ }^{6}$. This likely occurs because feedwater continues to sublimate even during the period of zero applied heat load because the water is exposed to the vacuum environment. The test coupon did not appear to be susceptible to failure caused by the expanding ice located in the reservoir. Resultantly, the project plans to repeat the tests in GFY 2010 using a flight sublimator designed for $\mathrm{X}-38$. Rather than using a heater to apply the heat load (as was done during the coupon tests), a varying temperature coolant loop will be used.

RADIATORS - Radiator advancement is perhaps the most critical technology development for the upcoming Lunar missions (and most other future spacecrafts, for that matter). NASA has no history of using radiators to reject the excess heat from a habitable vehicle on the Lunar surface. The Lunar Excursion Module (LEM) relied on an evaporator, specifically a sublimator, during its relatively short surface stay and the Lunar rovers only used a radiator to refreeze the PCM heat exchangers. However, because of the longer surface stay requirement of seven days (LEM was only three days) the use of an evaporator is not mass efficient for the Altair and Lunar habitat heat rejection requirements. The project's radiator development is further divided into two sub-elements. The first sub-element is the development of a variable heat rejection radiator and the second is an assessment of radiator performance with dust accumulation.

One of the most significant design challenges encountered when developing a radiator is liquid freezing within the coolant lines attached to the radiator surface. Typically radiators remove energy from the coolant lines flowing through the radiator and reject that energy to space. Radiator surface area is one of the key factors contributing to the rate at which energy is rejected to space. Generally speaking, radiators are sized for the maximum heat load in the warmest continuous thermal environment. In order to dissipate a high heat load in a relatively warm environment, it is necessary to design a radiator system with a large surface area. However, when that same large radiator is required to dissipate a much lower heat load in a cold environment, the surface temperature dramatically decreases. This decreased surface temperature can lead to fluid freeze within the radiator coolant lines if the radiator is not correctly designed. The resultant frozen fluid can be problematic and both Altair and Lunar Habitat face this exact design challenge. The radiator must be designed to dissipate a high heat load during Lunar surface operations, but must also be capable of operations at very low heat loads during the translunar coast. Translunar coast is extremely cold because the Altair radiators (and possibly the Lunar Habitat radiators) will be shadowed from the sun during the entire mission phase. The requirement to operate at both a high load and low load is referred to as the system turndown ratio $\left(Q_{\max } / Q_{\min }\right)$. Both Altair and the Lunar Habitat have approximately the same turndown ratio requirement. The requirement for these vehicles is an order of magnitude greater than the Apollo condition. The previously described design requirements are defined in Figure 10. 


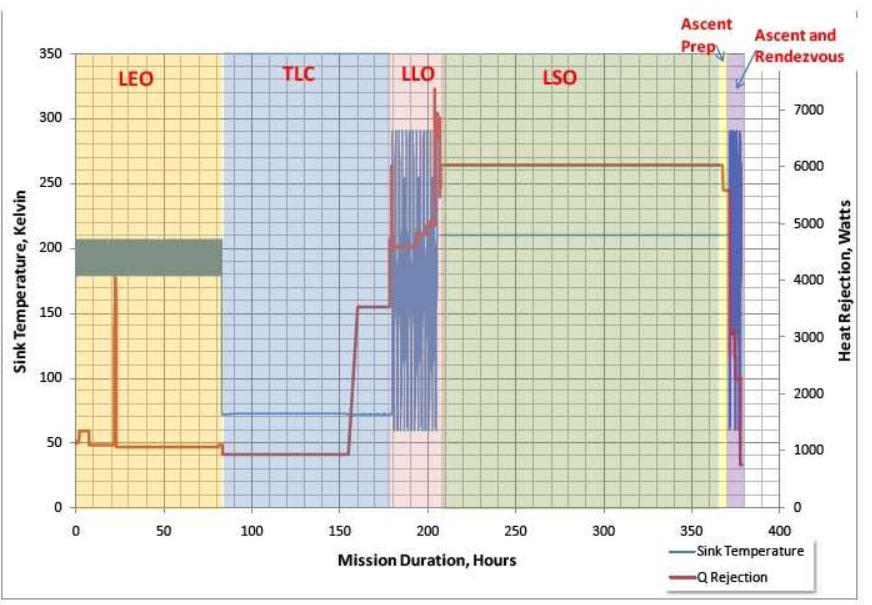

Figure 10. Altair heat rejection requirements and radiator sink temperatures plotted as a function of Mission Elapsed Time (MET).

The preceding figure shows both the radiator sink temperature and the vehicle's heat rejection requirement as a function of Mission Elapsed Time (MET). The radiator sink temperature, which is defined as the temperature that would be achieved for an adiabatic body with similar optical properties, is shown along the left, vertical axis. Due to the abscissa resolution, it is difficult to discern the transient nature. However, the radiator sink temperature repeats during each orbit period. The orbit period during LEO and LLO is approximately $1 \frac{1}{2}$ and two hours, respectively. The sink temperature varies from approximately 65 Kelvin during TLC and is as high as 290 Kelvin during LLO. As mentioned above, the radiator system is sized for Lunar surface operations, which corresponds to a sink temperature of 210 Kelvin.

The vehicle's heat rejection requirement is shown along the right, vertical axis is as low as 1000 Watts during TLC. However, there are times during the mission where the heat load exceeds 7000 Watts. For the design point, the heat rejection requirement is approximately $6 \mathrm{~kW}$.

For most manned vehicles, a high turndown ratio requirement usually results in a two-loop thermal control system architecture. A two-loop architecture is advantageous because the external loop can include a fluid with a very low freezing temperature. Unfortunately, fluids with low freezing points (Freon $₫$, ammonia, etc...) are typically toxic and cannot be located inside the pressurized volume due to crew safety concerns. The biggest drawback to a dual-loop system is the increased mass associated with both loops. The addition of a second loop requires several additional hardware components and a slight increase in the required radiator area due to inefficiencies associated with an interchange heat exchanger. Orion originally baselined a single loop system, but quickly switched to a two-loop system. The addition of the second loop increased the thermal control system mass by approximately $18 \%^{7}$.
The Advanced Thermal project is seeking to use technology development to overcome this extremely difficult design challenge. The project is pursuing the development of three separate variable heat rejection radiator technologies. These technologies include variable emissivity electrochromics ${ }^{8}$, a digital radiator ${ }^{9}$, and a freezable radiator ${ }^{10}$ design. In the preceding year, the project has design and tested thermal vacuum test samples or bench-top apparatuses to evaluate these technologies. Presently, the project is designing three full-scale radiators to meet the requirements shown in Figure 10. These designs will be compared and engineering development units will be developed to further evaluate the three promising technologies.

In addition to the previously described challenge, the Lunar surface environment presents yet another challenge to the radiator design process. From a thermal perspective, the negative impact of excessive regolith build-up on the radiator is twofold. First, the presence of regolith adds an extra thermal resistance between the radiator surface and the heat rejection environment. The thermal resistance of the Lunar regolith is extremely high due to the voids between the regolith particles. In other words, the regolith is a very good thermal insulator. The second negative effect caused by the deposition of regolith on a radiator surface is an increase in the solar absorptivity (or possible reduction in IR emissivity). Radiator surfaces are typically covered with selective thermal coatings to minimize the amount of solar energy absorbed by the surface. The Lunar regolith has a very high solar absorptivity, which results in the radiator surface absorbing excess thermal energy.

The project has completed thermal vacuum tests and the detailed results are presented in another paper ${ }^{11}$. The tests have shown that monolayer dust accumulation does not significantly impact the radiator's infrared emissivity as shown in Figure 11.

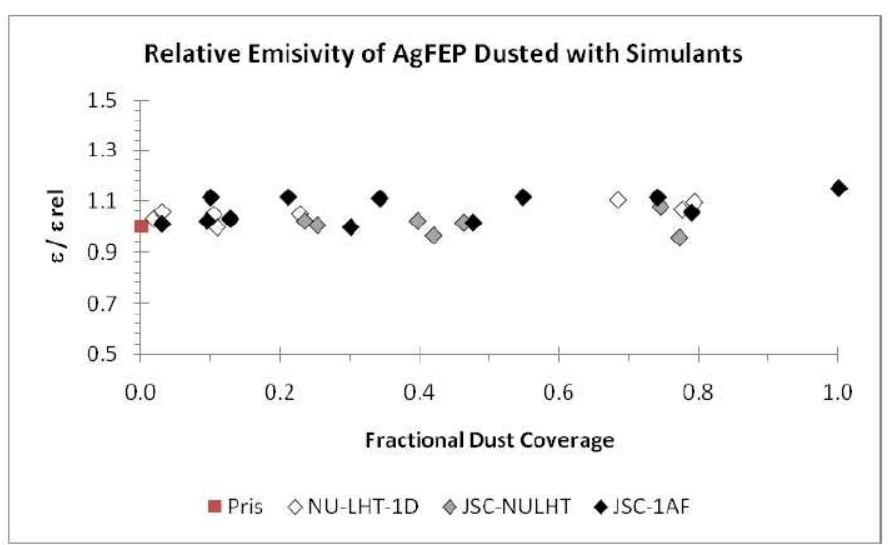

Figure 11. Relative infrared emissivity of silverized teflon tape as a function of fractional dust coverage.

Figure 11 shows the relative emissivity, which is a ratio of the dusted sample emissivity to the pre-dusted sample emissivity as a function of fractional dust coverage. As shown in this figure, the ratio remains near unity for 
fractional dust coverage up to 1 , which represents complete coverage. In addition, these tests also showed that accumulation does not adversely increase the thermal resistance.

However, the same tests have shown that monolayer dust accumulation can have a significant impact on the radiator's solar absorptivity. The relative absorptivity as a function of fractional dust coverage is shown in Figure 12.

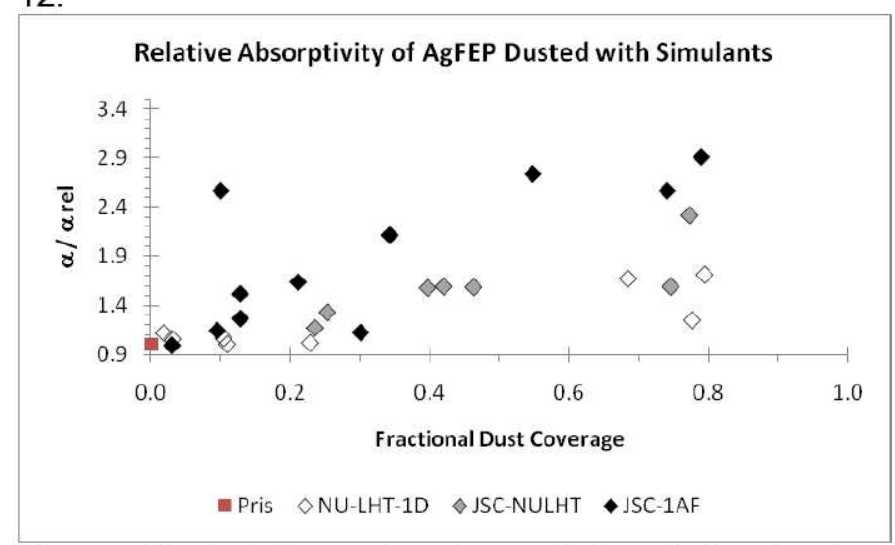

Figure 12. Relative solar absorptivity of silverized teflon tape as a function of fractional dust coverage.

Unlike Figure 11, Figure 12 shows a strong correlation between the fractional dust coverage and the radiator's optical property. The relative solar absorptivity tends to increase dramatically as the fractional dust coverage is increased. In addition, there appears to be a strong relationship between the absorptivity of the simulant and the impact of the accumulation. For example, the effect of accumulated JSC-1AF is much more severe than the impact of NU-LHT-1D. This is likely due to the fact that the solar absorptivity of the latter is lower than JSC-1AF. These results show that the solar absorptivity of a radiator surface can increase by as much as $50 \%$ when less than $20 \%$ of the radiator is covered with regolith. This increase would result in 1.5 times the amount of solar energy being absorbed by the radiator, which would severely impact the radiator's thermal performance.

The Advanced Thermal project is collaborating with another ETDP project to evaluate possible dust mitigation techniques. These mitigation techniques include workfunction matching, surface texturing, surface brushing, and electrodynamic shield technologies.

PHASE CHANGE MATERIAL HEAT EXCHANGERS - A typical PCM heat exchanger is used to store excess thermal energy during periods of high heat loads (or hot thermal environments) by melting a material and rejecting the stored energy at a later time. During the rejection period, the material is frozen again preparing it for the next heat load period.

The Advanced Thermal project has identified two PCM applications within the planned Lunar missions. The first known application is the Lunar Electric Rover (LER).
The baseline LER includes the use of a PCM heat exchanger conductively attached to a radiator. The second known PCM application is Orion. Orion's concept of operations includes a six-month LLO loiter. As mentioned in the preceding section discussing the transient sublimator, the LLO thermal environment is quite unique and results in the need of a supplemental heat rejection device. A PCM heat exchanger is well suited for this application due to the relatively long and cyclic LLO mission phase (currently scheduled for six months). In addition to these possibilities, a PCM heat exchanger development effort also provides risk mitigation for the transient sublimator development.

The amount of PCM mass required to provide thermal control for a PCM application is inversely related to the material's heat of fusion. The higher the heat of fusion, the lower the required PCM mass as shown in Equation 2.

$\mathrm{m}=\frac{\mathrm{E}}{\mathrm{h}_{\mathrm{f}}}$

Equation 2

Where:

$$
\begin{aligned}
& m=\text { Mass of phase change material (kilograms) } \\
& E=P C M \text { energy storage requirement (Joules) } \\
& h_{f}=\text { PCM heat of fusion (Joules/kilogram) }
\end{aligned}
$$

Water has a heat of fusion almost $70 \%$ higher than a typical PCM with the appropriate control (melt) temperature. Therefore, the use of water as the PCM would significantly reduce the required heat exchanger mass. Of course, there are some unique challenges associated with the use of water as the PCM. Unlike most fluids, water expands when it freezes which results in unique structural design challenges.

The Advanced Thermal project is developing two types of ice PCM heat exchangers. The two types of heat exchangers use the same phase change material (water), but have a subtle difference in the method which the energy is added to and removed from the heat exchanger.

The first heat exchanger will be designed to interface with a traditional active thermal control system. The energy would be added to and removed from the PCM by a pumped fluid loop flowing through the PCM hardware. This type of heat exchanger is planned to be used on Orion. The project has worked with Energy Sciences Laboratory (ESLI) to develop several ice PCM heat exchangers for evaluation. The first heat exchanger, Replicative Ice PCM (RIP), was designed to replicate the energy storage of an existing paraffin-based PCM heat exchanger. Due to water's higher heat of fusion, RIP is much lighter and smaller than the baseline. The two units are shown in Figure 13. 


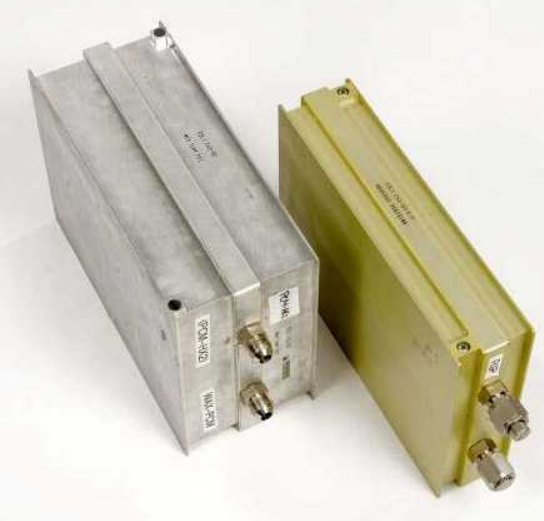

Figure 13. Size comparison between paraffin-based PCM and Replicative Ice PCM (RIP).

The final RIP mass is approximately $5.4 \mathrm{~kg}$ while the baseline heat exchanger mass is $8.4 \mathrm{~kg}$. In addition to this significant mass savings, the RIP heat exchanger volume is only $3500 \mathrm{~cm}^{3}$ compared to $6600 \mathrm{~cm}^{3}$ for the paraffin-based PCM heat exchanger ${ }^{12}$.

In addition to the replicative ice PCM heat exchanger, the project collaborated with ESLI to develop two smaller icebased PCM heat exchangers as shown in Figure 14.

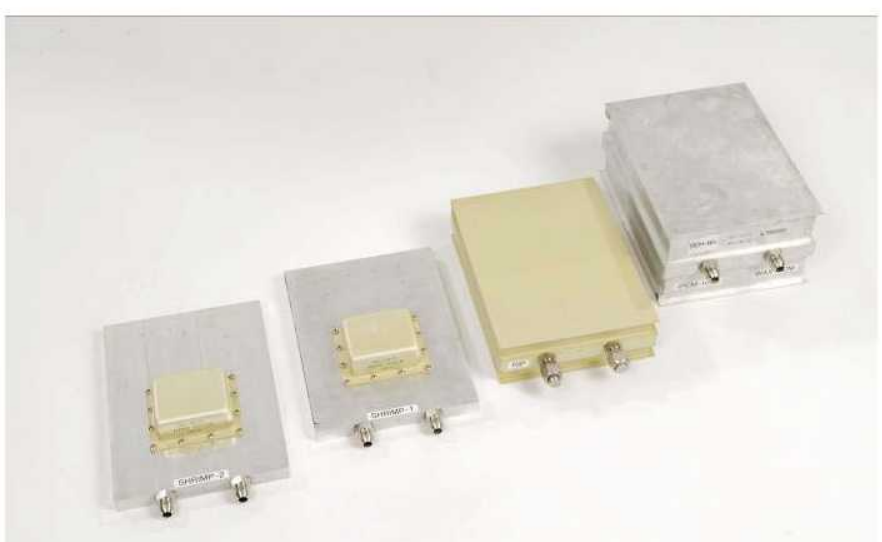

Figure 14. PCM heat exchangers developed in collaboration with ESLI. From left to right; SHRIMP. 1, SHRIMP-2, RIP, and the paraffin-based PCM heat exchanger.

In the preceding figure, RIP is shown as the third heat exchanger from the left. The two smaller ice-based heat exchangers, SHRIMP-1 and SHRIMP-2 (Small Heat sink of Replicative Ice Material for Phase change) were developed to assess the feasibility of using water as the phase change material in a very cost effective manner. SHRIMP-1 incorporated the same interstitial material configuration as RIP. SHRIMP-2, on the other hand, was designed to create a void space between the aluminum fins rather than randomly located void spaces throughout the heat exchanger. All of the water-based heat exchangers were filled with water to approximately $80 \%$ of the void volume. Each of the preceding heat exchangers was exposed to several freeze/thaw cycles in both favorable and adverse (if applicable) gravity orientations. RIP was exposed to a total of five freeze/thaw cycles while both SHRIMPs were cycled 45 times during the test program. Unfortunately, each of the heat exchangers failed due to the expansion of ice during the freeze cycles. A detailed description of this test program is provided by Leimkuehler, et. al.

The second water-based PCM heat exchanger being developed by the Advanced Thermal project is critical for the Lunar Electric Rover. This heat exchanger will not interface with a coolant loop. The energy will be transferred to the phase change material through an air duct. The PCM heat exchanger is integrated with a radiator to refreeze the phase change material when the heat load is decreased or the thermal environment is more benign. The LER is an ideal application due to the transient nature of the vehicle's heat rejection requirement as shown in Figure 15.

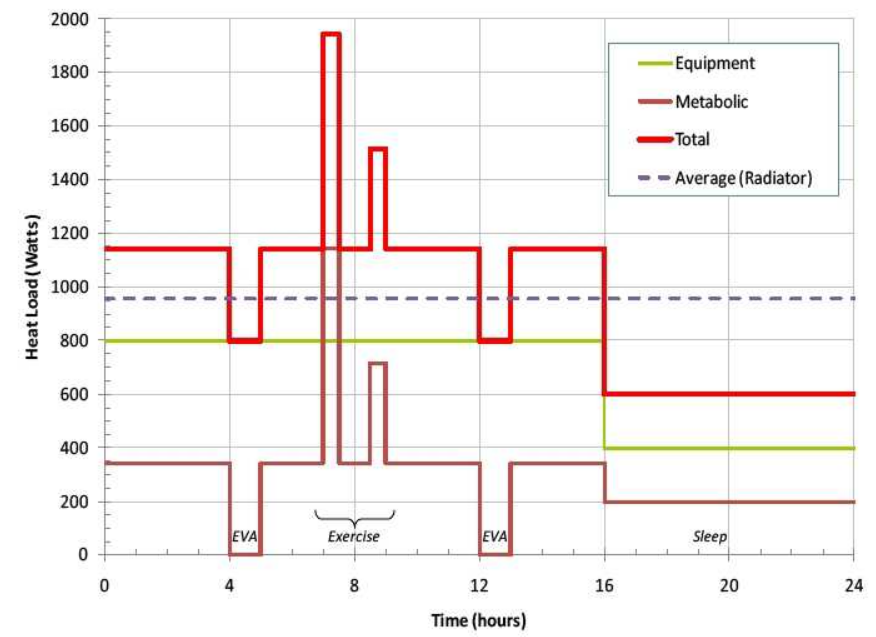

Figure 15. Lunar Electric Rover (LER) heat rejection profile.

Typically, radiators are sized for the maximum heat load in the warmest continuous thermal environment. Using the heat rejection profile shown in Figure 15 as an example, the vehicle's radiator would have to be sized for nearly 1900 Watts. However, because the vehicle's thermal control system includes a phase change material heat sink, the radiator can be sized for the average heat rejection requirement which is only 950 Watts thereby resulting in a smaller radiator.

The project designed and fabricated a total of three PCM heat sinks that were included in a thermal vacuum test program. One of the test articles is shown in Figure 16. 


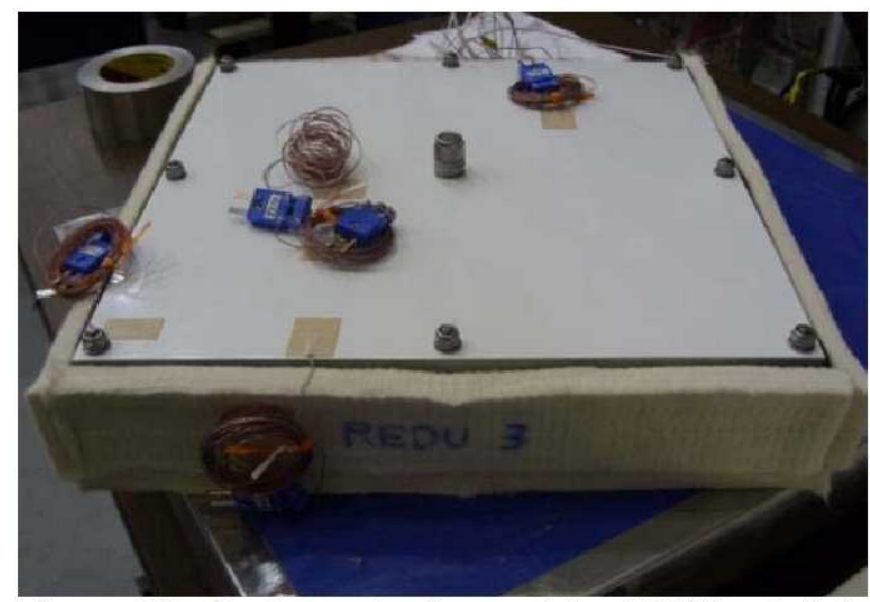

Figure 16. Photograph of one of the PCM heat sink test articles showing the nomex insulation and the "radiator" lid.

While the preceding figure clearly shows the sides and the lid, the heater is not shown. The test article can be thought of as a six-sided box with the "radiator" lid as the top surface. For this test article, the heat load is applied using a strip heater adhered to the bottom surface. The test articles were installed into the thermal vacuum chamber as shown in Figure 17.

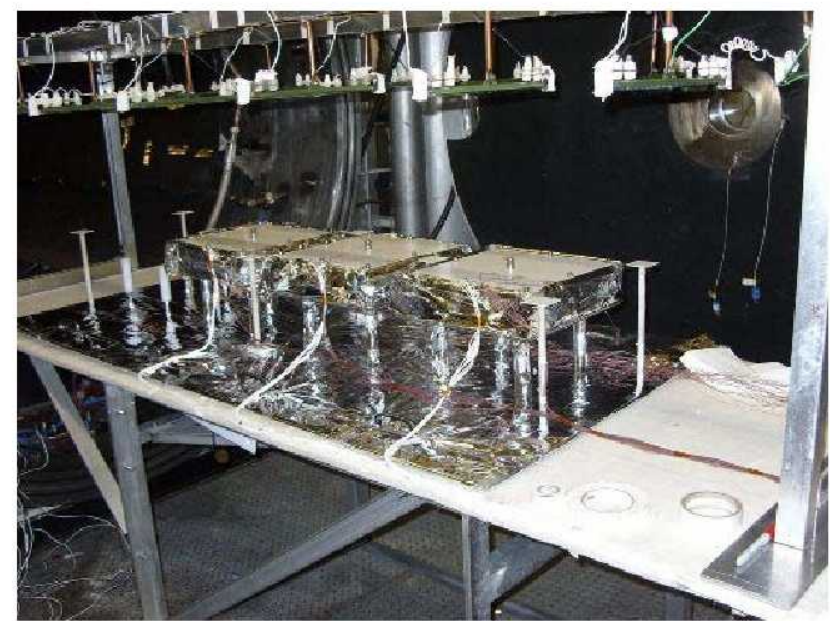

Figure 17. The three test articles installed in the thermal vacuum chamber. The infrared lamps used to control the environmental temperature are shown on the top.

A test article transient heat load, which was scaled using the data shown in Figure 15, was applied to the bottom side of the test article using the aforementioned strip heaters. In addition to this simulated mission profile, several freeze/thaw cycles were also performed. The fabrication of the test articles and the subsequent test program demonstrated proof-of-concept that a phase change material heat sink can be integrated with a radiator and used to provide the heat rejection/storage function of a thermal control system ${ }^{13}$.

\section{CONCLUSION}

NASA's Exploration Technology Development Program includes several projects performing technology development for the Constellation Program. One of these projects is the Thermal Control System Development for Exploration project (Advanced Thermal project). The Advanced Thermal project's objectives are to develop viable solutions for thermal design challenges and to mitigate key risks for Orion, Altair, and Lunar Surface Systems through technology development. While the project is currently focused on the Constellation Program, the overwhelming majority of the development efforts are generically applicable to any spacecraft thermal control system.

The technology development process begins with technologies possessing a TRL of approximately two or three and advances them to a TRL of six. The TRL six is achieved by completing an integrated thermal test approximately one year prior to the customer's Preliminary Design Review.

The project's portfolio is very broad and includes thermal control system fluids, heat acquisition hardware, and evaporative heat sinks. In addition to these elements, the project is also focused on developing spacecraft radiators. The final element within the project's portfolio is the advancement of Phase Change Material heat exchanger and heat sinks. These devices are currently being developed for Orion and the Lunar Electric Rover.

\section{ACKNOWLEDGMENTS}

The author of this paper is the project manager for the technology development project. The author would like to thank all of the individuals involved with making this a successful project. The project members are from a variety of NASA field centers including GRC, JPL, and JSC. In addition to this dedicated workforce, the project also collaborates with various industry partners including Pacific Northwest National Laboratories, Energy Science Laboratories, Paragon Space Development, Jacobs Engineering, Oceaneering Space Systems, Hamilton Sundstrand, and Ashwin-Ushas Corporation. The author would also like to thank his division management and Altair project office personnel for giving him the opportunity to work on the next generation Lunar lander. None of this could have been accomplished without the support of the program office and all of the helpful and enthusiastic individuals working in that office.

\section{REFERENCES}

1. Sheth, R. B., Stephan, R. A., Leimkuehler, T. O. "Sublimator Driven Coldplate Engineering Development Unit Test Results and Development of Second Generation SDC." AIAA ICES Paper xxICES-xxxx. July 2010.

2. Stephan, R. A. "Overview of NASA's Thermal Control System Development for Exploration Project." SAE ICES Paper 09ICES-0351. July 2009. 
3. Lee, S. A. "Evaluation of a Thermal Control Fluid for Constellation Vehicles." AIAA ICES Paper xxICESxxxx. July 2010.

4. Shin, E. E., Johnston, J. C. "Design and Development of Lightweight Air-Liquid Composite Heat Exchangers for Space Exploration Applications." AIAA ICES Paper xxICES-xxx. July 2010.

5. Hawkins-Reynolds, E., Le, H. V., Stephan, R. A. "Development, Fabrication, and Testing of a Liquid/Liquid Microchannel Heat Exchanger for Constellation Spacecrafts." AIAA ICES Paper xxICES-Xxx. July 2010.

6. Sheth, R. B., Stephan, R. A., Leimkuehler, T. O. "Investigation of Transient Performance for a Sublimator." AIAA ICES Paper xxICES-xxxx. July 2010.

7. Ochoa, D. A., Ewert, M. "A Comparison Between One- and Two-Loop ATCS Architectures Proposed for CEV." SAE ICES Paper 09ICES-0353. July 2009.

8. Bannon, E. T., Bower, C. E., Sheth, R. B. "Electrochromic Radiator Coupon Level Testing and Full Scale Thermal Math Modeling for Use on Altair Lunar Lander." AIAA ICES Paper xxICES-xxxx. July 2010.

9. Sunada, E., Birur, G. C., Ganapathi, G. B., Miller, J., Berisford, D., Stephan, R. A. "Design and Testing of an Active Heat Rejection Radiator with Digital TurnDown Capability." AIAA ICES Paper xxICES-xxxx. July 2010.

10. Lillibridge, S. T., Navarro, M., Cognata, T., Guinn, J. "Freezable Radiator Testing." AIAA ICES Paper xxICES-xxxx. July 2010.

11. Gaier, J. R. "Effect of Simulant Type on the Absorptivity and Emissivity of Dusted Thermal Control Coatings in a Simulated Lunar Environment." AIAA ICES Paper xxICES-xxxx. July 2010.

12. Leimkuehler, T. O., Hansen, S., Stephan, R. A. "Development, Testing, and Failure Mechanisms of a Replicative Ice Phase Change Material Heat Exchanger." AIAA ICES Paper xxICES-xxxx. July 2010.

13. Lee, S. A., Leimkuehler, T. O., Stephan, R. A., Le, H. V. "Thermal Vacuum Test of Ice as a Phase Change Material Integrated with a Radiator." AIAA ICES Paper xxICES-xxxx. July 2010.

\section{CONTACT}

Ryan A. Stephan

Ryan.A.Stephan@nasa.gov

\section{ACRONYMS \& ABBREVIATIONS}

ATCS: Active Thermal Control System

CxPO: Constellation Program Office

EDU: Engineering Development Unit

ESLI: Energy Science Laboratories, Inc.

ESMD: Exploration Systems Mission Directorate

ETDP: Exploration Technology Development Program

ISS: International Space Station

JSC: Johnson Space Center

LEM: Lunar Excursion Module

LER: Lunar Electric Rover

LLO: Low Lunar Orbit

LSS: Lunar Surface Systems

MIPR: Military Interdepartamental Purchase Request

OAFU: Orbit-Averaged Feedwater Utilization

PCM: Phase Change Material

PDR: Preliminary Design Review

PNNL: Pacific Northwest National Laboratories

RIP: Replicative Ice PCM

SDC: Sublimator Driven Coldplate

SHReD: Supplemental Heat Rejection Device

TCS: Thermal Control System

TRL: Technology Readiness Level

VIO: Vehicle Integration Office

WBS: Work Breakdown Structure

A: Radiator surface area

$\varepsilon$ : Infrared emissivity

E: Phase change material energy storage requirement

$\mathbf{h}_{\mathrm{fg}}$ : Phase change material heat of fusion

K: Kelvin

$\mathbf{m}$ : Mass of phase change material

$\mathbf{m}^{2}$ : Square meters

Q: Radiator heat rejection

$\mathbf{Q}_{\max }$ : Maximum system heat rejection requirement

$\mathbf{Q}_{\min }$ : Minimum system heat rejection requirement

$\sigma$ : Stefan-Boltzman constant

$\mathbf{T}_{\infty}$ : Radiator sink temperature

$\mathbf{T}_{\mathbf{R}}$ : Average radiator temperature

$\mathbf{W}$ :Watts 